International Journal of Engineering \& Technology, $7(2.24)(2018) 63-68$
International Journal of Engineering \& Technology
SPC
Website: $w$ ww.sciencepubco.com/index.php/IJET
Research paper

\title{
Single Stage Boost Integrated High-Frequency Full Bridge Inverter for Induction Heating System
}

\author{
Arul Prakash Jayachandran', Booma Nagarajan², Akshaya ${ }^{3}$, Mabel Jemima $A^{4}$, Asaipriyan $S^{5}$ \\ ${ }^{1}$ Research Scholar, ${ }^{2}$ Professor \\ Department of Electrical and Electronics Engineering, Jerusalem College of Engineering Chennai-100 \\ *Corresponding Author Email: arul.jce@gmail.com
}

\begin{abstract}
This paper proposes a new single-stage boost high frequency ac series resonant power inverter for high frequency induction heating (IH) applications. The proposed ac-ac converter consist of a single stage boost (SSB) converter and full-bridge ac series resonant inverter integrated circuit with a ac source voltage control strategy by controlling the inverter switches. The Simulink model is developed using MATLAB simulation software and the simulated results are examined. The output power is maintained to the required level by using phase shift control strategy and the simulated results are validated.
\end{abstract}

Index Terms: Phase-shift control, Single stage boost inverter, and induction heating.

\section{Introduction}

Nowadays high frequency induction heating (IH) has been used in most of the industrial application such as hardening, bracing heating treatment etc. The merits of induction heating is the capability of partial heating, fast and efficient response for load power variations an so on. [1] The process of power conversion from low frequency ac to the high-frequency ac the ac series resonant inverter is used which is commonly used inverter topology for induction heating application. Fig. 1. shows a commonly used process stages diagram. In that process contains generally three parts has to use which consists of diode bridge rectifier for converting the ac supply in to the dc supply, a boost converter which is for boosting the input voltage to the required level, and a high frequency series resonant inverter which produces the ac supply by converting the given dc with required frequency. Since for improving the efficiency of the inverter and also reducing the components cost of the circuit, a single-stage boost (SSB) Integrated Inverter have been proposed [2]-[6]. In the proposed paper, instead of a full-bridge diode rectifier and a separate boost converter and inverter circuit a single stage boostinverter-integrated circuit is developed, which ensures the boost operation and inverter operation whose operating frequency is as resonant frequency and also ensures the reduction in the conduction losses in the circuit by avoiding the diodes in the circuit [6].

A single stage boost full- bridge inverter is proposed in this paper. The proposed paper consists of ac-boost-ac converter in which boost operation in a single stage and series full-bridge inverterintegrated system by sustaining the advantages of diode rectifier as a SSB power doubling process.

And also the required voltage as well as power level is maintained by using Phase Shift Control strategy, which ensures the simple power control operation of the SSB. Fig. 2. shows the integrated SSB-inverter scheme.

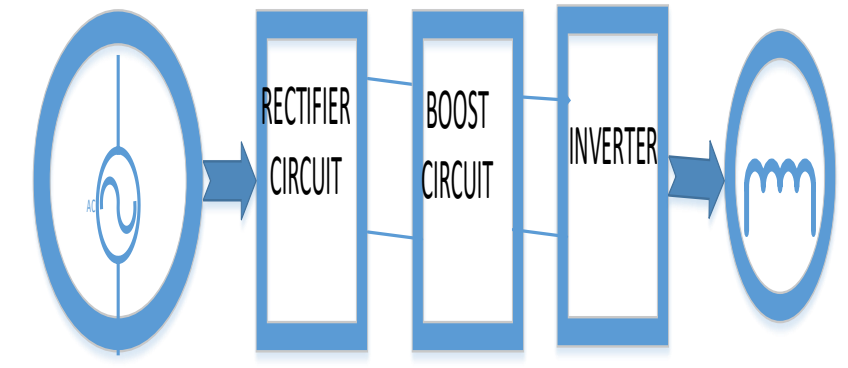

Fig. 1: Convention Power conversion process stages

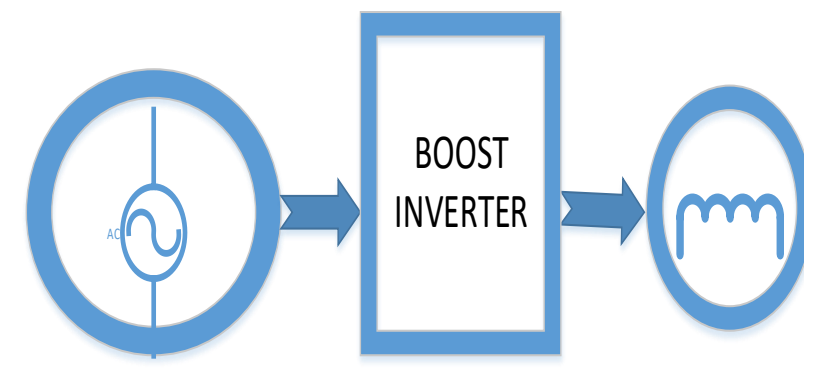

Fig. 2: Single-Stage Power conversion process stages

In this paper, a simulation of the proposed circuit is developed and the results are examined. The organization of the paper the circuit configuration along with the phase-shift power control of the SSBintegrated inverter are explained, and further the principle of operation of the proposed circuit is also explained.

\section{Principle and Operation of Proposed Circuit}

\section{A. Control Strategy}


The proposed single stage boost (SSB)-integrated inverter circuit is described in Fig. 3. The AC voltage input $\mathrm{V}_{\text {in }}$ is converter in to DC by using the diodes $\mathrm{D}_{5}$ and $\mathrm{D}_{6}$, then the voltage is boosted by the inductor $L_{b}$. The two switches leading $S_{1}-S_{2}$ is the fixed leg and the two switches lagging $\mathrm{S}_{3}-\mathrm{S}_{4}$ operates as the control leg. The snubber capacitors $\mathrm{Cs}_{1}-\mathrm{Cs}_{4}$ connected across the corresponding switch $S_{1}-S_{4}$ which is not shown for simplicity. $S_{1}$ - $\mathrm{S}_{4}$ along with the load inductance $\mathrm{L}_{\mathrm{o}}$ of the IH. The low-pass filter consists of $L_{\mathrm{f}}$ and $C_{\mathrm{f}}$ avoids switching-frequency component of $i$ in.

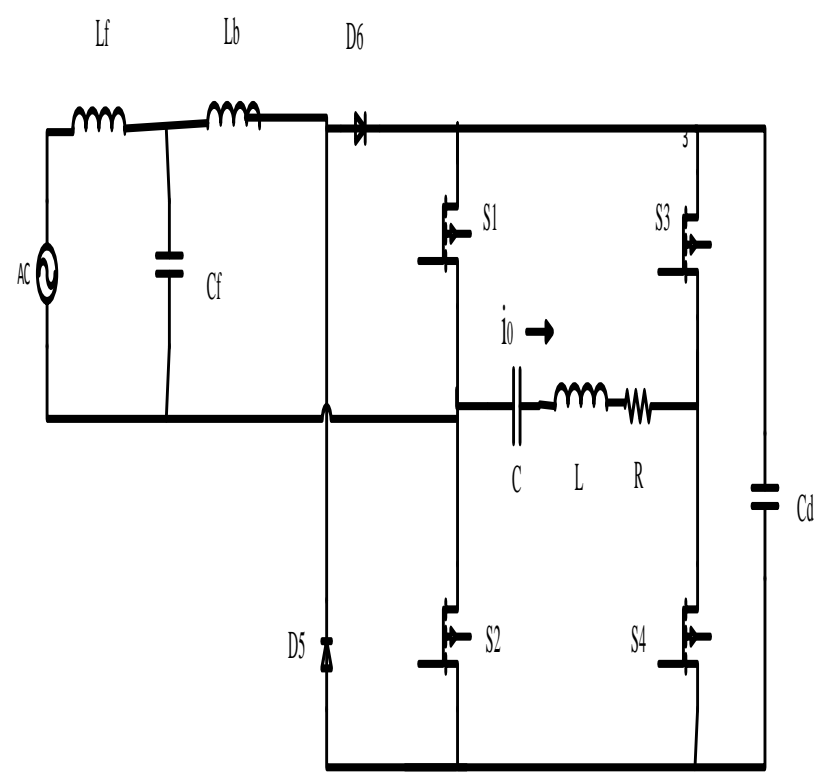

Fig. 3: Single Stage Boost-Integrated Inverter converter

The output voltage $\mathrm{v}_{o}$, output current $\mathrm{i}_{o}$ and instantaneous output power $p_{O}$ is controlled and detected by the SSB full bridge inverter and the control circuit can be expressed by equations are given below.

$v_{0}=\sqrt{2} V_{0 r} \sin \omega_{r} t+\sqrt{2} V_{0 s 1} \sin \omega_{h 1} t+\sum_{n=3,5 \ldots} \sqrt{2} V_{0 s n} \sin \omega_{s n} t$

$i_{0}=\sqrt{2} I_{0 r} \sin \omega_{r} t+\sqrt{2} I_{0 s 1} \sin \omega_{h 1} t+\sum_{n=3,5 \ldots} \sqrt{2} I_{0 s n} \sin \omega_{s n t} t$

$$
\begin{aligned}
P_{0}= & V_{0 r} I_{0 r} \cos \theta_{r}-\sin \left(2 \omega_{r} t-\theta_{r}\right)+ \\
& V_{0 s 1} I_{0 s 1} \cos \theta_{s n} \sin \left(2 \omega_{s n} t-\theta_{s n}\right)+ \\
& \sum_{n=3,5 \ldots} V_{0 s n} I_{0 s n} \cos s n \theta_{s n}-\sin \left(2 \omega_{s n} t-\theta_{s n}\right)
\end{aligned}
$$

$P_{0}=V_{0 r} I_{0 r} \cos \theta_{r}+V_{0 s 1} I_{0 s 1} \cos \theta_{s n}+$

$$
\sum_{n=3,5 \ldots} V_{0 s n} I_{0 s n} \cos s n \theta_{s n}
$$
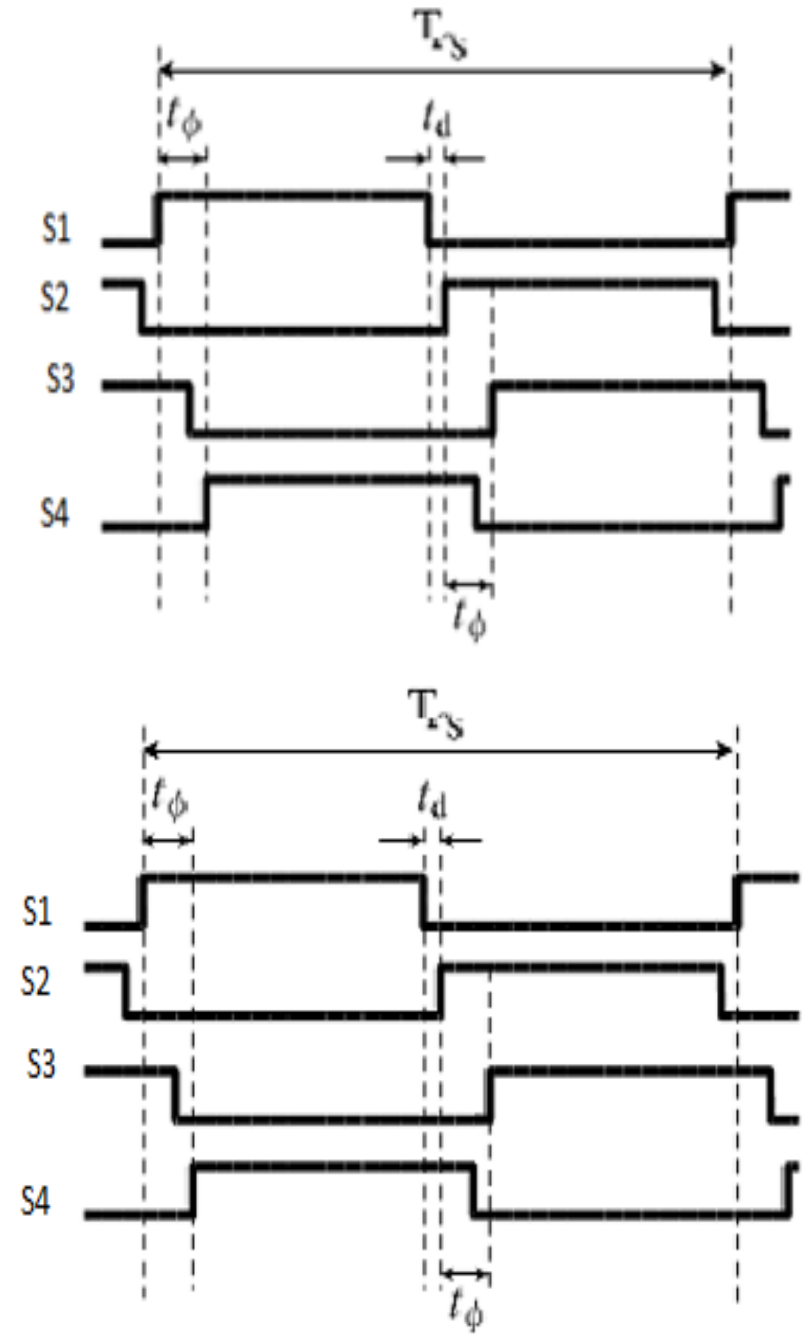

Fig. 4: Switching pulse pattern of phase shift control technique

Where the load switching frequency is $\omega_{\boldsymbol{u}}=2 \pi f_{\boldsymbol{u}}, \omega_{\boldsymbol{h} 1}=$ $2 \pi f_{S}$, and phase angles is $\omega h \boldsymbol{h}=n \cdot \omega h$. The power of the load is expressed in equation (4).

For switch S1 and S4 similarly S2 and S3 is controlled by the phase shift of $t \varphi$ time interval with the polarity of the supplied voltage and the phase shift time is expressed by equation (5)

$t_{0}=\frac{\phi}{360^{\circ}} T_{s}$

Where Time taken for one cycle is Ts. The output voltage as well as the current is controlled be controlled by the phase-shift control. The output RMS voltage $\mathrm{V}_{\text {os } 1}$ and the output RMS current $\mathrm{I}_{\mathrm{os} 1}$ are expressed in equation (6) and (7) respectively.

$$
\begin{aligned}
& V_{0 s 1}=\frac{2 \sqrt{2} V_{i n}}{\pi} \cos \phi, I_{0 s 1}=\frac{V_{0 s 1}}{Z_{0}} \\
& Z_{0}=\sqrt{R_{0}^{2}+X_{0}^{2}} \quad X_{0}=\omega_{s} L_{0}-\frac{1}{\omega_{s} C_{0}}
\end{aligned}
$$

Equation (7) shows the load impedance of the circuit

\section{B. Operation Principle}

Fig. 5. Shows the gate switching sequence, output voltage and output current waveforms together of the SSB converter for a high switching frequency cycles. And also the transitions mode for the proposed circuit and also for one switching cycle are shown in Fig. $6(a)$ 


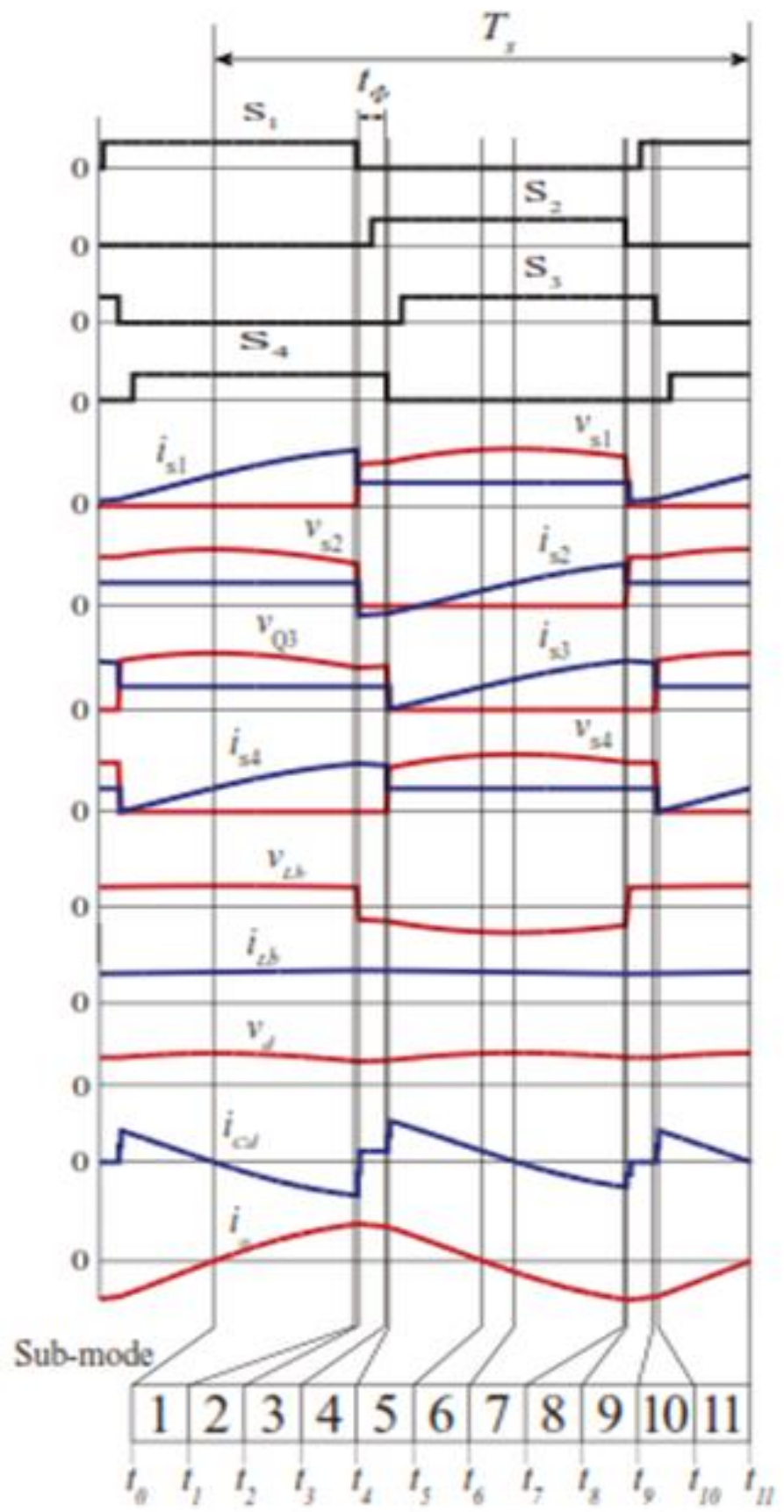

Fig. 5: Switching Transition Modes

Mode 1: $\left(\mathrm{t}_{0} \leq \mathrm{t}<\mathrm{t}_{1}\right)$ In this mode Capacitor $\mathrm{C}_{\mathrm{d}}$ discharges during this interval of time. The switches $S_{1}$ and $S_{4}$ are $O N$, and the current $i_{o}$ flows through the source to load.

Mode 2: $\left(\mathrm{t}_{1} \leq \mathrm{t}<\mathrm{t}_{2}\right)$ the switch $\mathrm{S}_{1}$ is turned off at $\mathrm{t}_{1}$, and the snubbing capacitors $\mathrm{C}_{\mathrm{s} 1}, \mathrm{C}_{\mathrm{s} 2}$ and load inductance Lo make the resonance condition on the circuit

Mode 3: $\left(t_{2} \leq t<t_{3}\right)$ In this mode $v_{s 1}$ attains $v_{d}$ at time period $t_{2}$, and switch $S_{1}$ is commutated and the ZVS turn-off achieved.

Mode 4: $\left(t_{3} \leq t<t_{4}\right)$ In this mode the switch $S_{4}$ is OFF at $t_{3}$ time period, IH load inductance $\mathrm{L}_{o}$ and the snubbing capacitors $\mathrm{C}_{\mathrm{s} 3}, \mathrm{C}_{\mathrm{s} 4}$ make the resonance condition.

Mode 5: $(\mathrm{t} 4 \leq \mathrm{t}<\mathrm{t} 5)$ In this mode $\mathrm{v}_{\mathrm{S}}$ attains vd at time period $\mathrm{t}_{4}$, $\mathrm{S}_{4}$ is OFF.

Mode 6: $\left(\mathrm{t}_{5} \leq \mathrm{t}<\mathrm{t}_{6}\right)$ In this mode due to resonance condition the output current $i_{o}$ changes such that it reverses its polarity at time period $t_{5}$

Mode 7: $\left(\mathrm{t}_{6} \leq \mathrm{t}<\mathrm{t}_{7}\right)$ In this mode the boost inductor $\mathrm{L}_{\mathrm{b}}$ deenergies capacitor $\mathrm{Cd}$ also starts discharging immediately. Mode 8: $\left(\mathrm{t}_{7} \leq \mathrm{t}<\mathrm{t}_{8}\right)$ In this mode the switch $\mathrm{S}_{2}$ is off at time $\mathrm{t}_{7}$, and load inductance Lo and the snubbing capacitors $\mathrm{C}_{\mathrm{s} 1}, \mathrm{C}_{\mathrm{s} 2}$ and the IH make the resonance.

Mode 9: $\left(\mathrm{t}_{8} \leq \mathrm{t}<\mathrm{t}_{9}\right)$ In this mode $\mathrm{v}_{\mathrm{S} 2}$ attains $\mathrm{v}_{\mathrm{d}}$ at time period $\mathrm{t}_{8}$, and the $S_{2}$ is OFF. Same time, the voltage vs1 reaches zero voltage.

Mode 10: $\left(t_{9} \leq t<t_{10}\right)$ In this mode switch $\mathrm{S}_{3}$ is turned off at the period $t 9$, and load inductor $L_{O}$ and the snubbing capacitors $C_{S} 3, C_{S} 4$ make the partial resonance in the circuit.

Mode 11: $\left(t_{10} \leq t<t_{11}\right)$ Voltage $v_{S 3}$ reaches $v_{d}$ at $t_{10}$, and $\mathrm{S}_{3}$ is turned OFF in this mode.

The output voltage across the load and the output current through the load in the SSB-integrated inverter topology are expressed as [6]

$$
v_{0, S S B}=v_{c 1}+v_{c 0}=v_{d}+v_{c 0}-v_{c 2}
$$




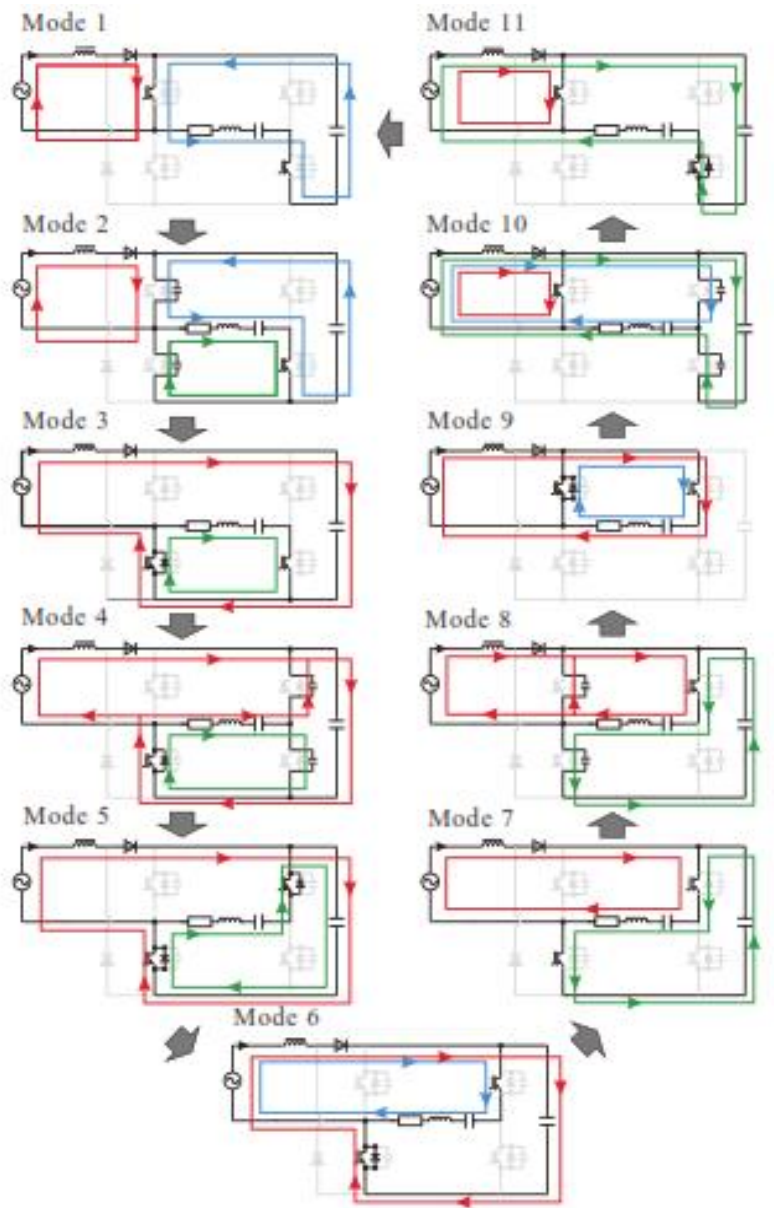

(a)

Fig. 6: (a) Positive polarity half cycle Switching Mode of operations

$i_{0, B H B}(t)=\frac{\omega_{1}^{2} C_{1} V_{c 1}(0)}{\sqrt{\omega_{1}^{2}-\alpha^{2}}} \varepsilon^{-\alpha t} \sin \gamma_{1} t$

$\alpha=\frac{R_{0}}{2 L_{0}}, \gamma_{1}=\sqrt{\frac{1}{L_{0} C_{r 1}}-\left(\frac{R_{0}}{2 L_{0}}\right)^{2}}, C_{r 1}=\frac{C_{0} C_{1}}{C_{0}+C_{1}}$

$v_{0, B H B}=v_{d}+v_{c} 0$

$i_{0, \text { Внв }}(t)=\frac{\omega_{2}^{2} C_{1} V_{c 1}(0)}{\sqrt{\omega_{2}^{2}-\alpha^{2}}} \varepsilon^{-\alpha t} \sin \gamma_{2} t$

$\gamma_{2}=\sqrt{\frac{1}{L_{0} C_{r 2}}-\left(\frac{R_{0}}{2 L_{0}}\right)^{2}}, C_{r 2}=\frac{C_{0} C_{1}}{C_{0}+C_{1}}$

From those equations we can understand that the output voltage across the load and output current through the SSB-intergated inveter are much higher than the other topologies.. Therefore, the boost full bridge topology is effective and best suitable controlling topolgy.

The boost inductor voltage $L_{b}$ is proposed in Fig. 6. (a) Since by taking the source voltage $\mathrm{V}_{\text {in }}$ as constant. $L_{b}$ becomes zero voltage when the source is continuous.

$v_{d}=2 v_{\text {in }}$

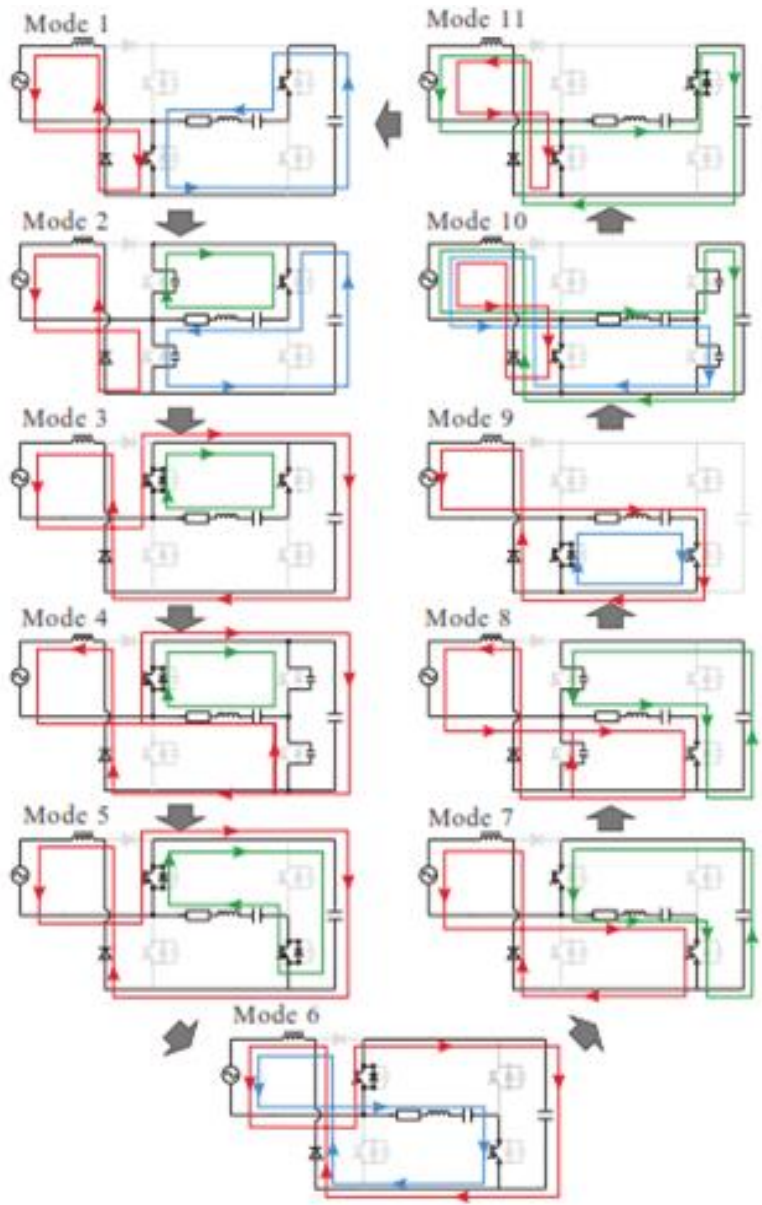

(b)

(b) Negative polarity half cycle switching mode of operations

\section{Simulation Results for proposed circuit}

To confirm the validity of the proposed Phase - Shift control technique the simulation study to be done. Table. 1. shows the parameter of proposed configuration of the induction heating system. The proposed Phase Shift control technique is simulated using MATLAB Simulink model in Fig. 7. the simulation results as follows. Fig. 8. shows the Phase - Shift Switching of $\mathrm{S}_{1}, \mathrm{~S}_{2}, \mathrm{~S}_{3}$ and $\mathrm{S}_{4}$, Fig. 9. shows the Voltage across RL load. Fig. 10. shows the voltage across the RLC. Fig. 11. shows the output current through load RL.

Table 1: Parameter of Proposed Configuration

\begin{tabular}{|l|l|l|}
\hline Item & Symbol & Value \\
\hline Source voltage & VDC & $50 \mathrm{~V}$ \\
\hline $\begin{array}{l}\text { Equivalent resistance of each } \\
\text { load }\end{array}$ & $\mathrm{R}_{\mathrm{eq}}$ & $1.2 \Omega$ \\
\hline Equivalent inductance of Coil 1 & $\mathrm{L}_{1}$ & $24 \mu \mathrm{H}$ \\
\hline $\begin{array}{l}\text { Resonant capacitance of each } \\
\text { load }\end{array}$ & $\mathrm{C}_{\mathrm{r}}$ & $300 \mu \mathrm{F}$ \\
\hline Filter inductance & $\mathrm{L}_{\mathrm{a}}$ & $200 \mu \mathrm{H}$ \\
\hline Boost inductance & $\mathrm{L}_{\mathrm{b}}$ & $500 \mu \mathrm{H}$ \\
\hline Filter capacitance & $\mathrm{C}_{\mathrm{f}}$ & $750 \mu \mathrm{F}$ \\
\hline Delay time in each leg & $\mathrm{t}_{\mathrm{d}}$ & $450 \mathrm{nsec}$ \\
\hline $\begin{array}{l}\text { Resonant frequency of load } \\
\text { circuit }\end{array}$ & $\mathrm{f}_{\mathrm{r}}$ & $20 \mathrm{kHz}$ \\
\hline $\begin{array}{l}\text { Switching frequency of each } \\
\text { leg }\end{array}$ & $\mathrm{f}_{\mathrm{s}}$ & $22 \mathrm{kHz}$ \\
\hline
\end{tabular}



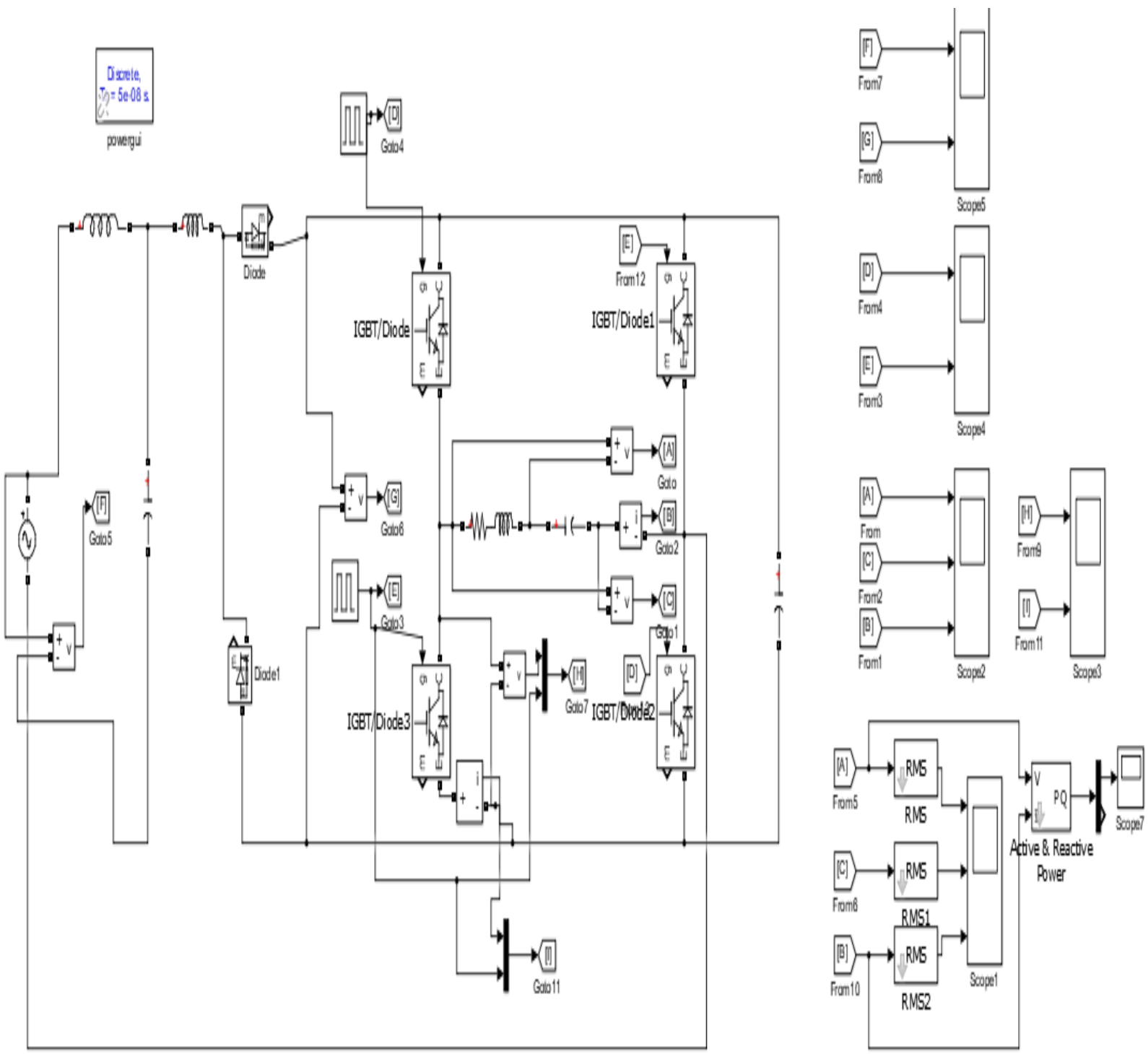

Fig. 7: Simulink Model of proposed Boost Series Full-Bridge High Frequency inverter

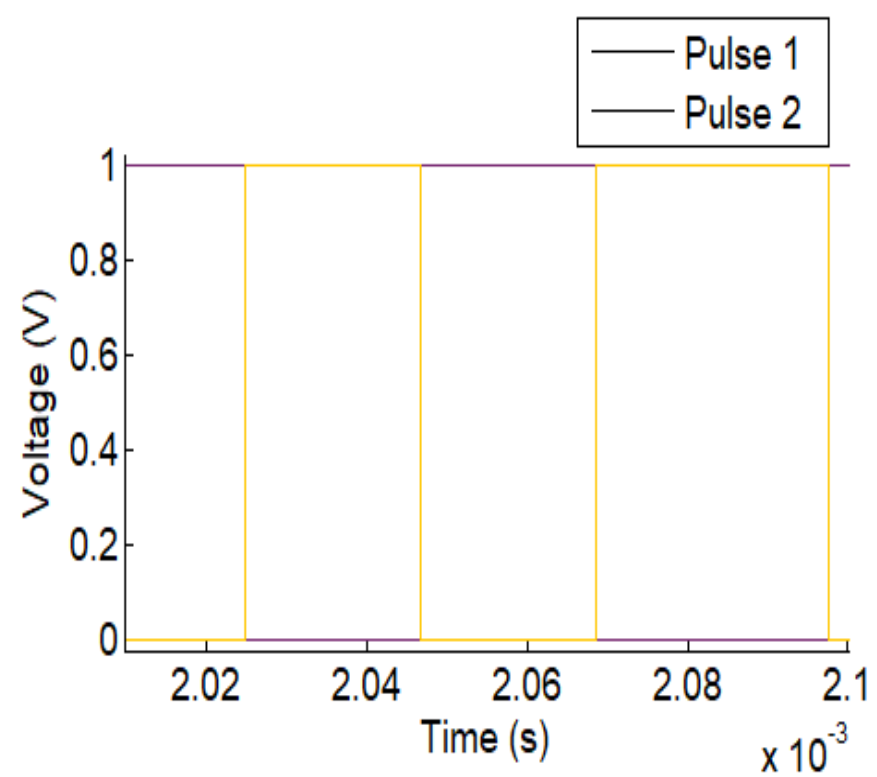

Fig. 8: Phase-Shift Switching of $S_{1}, S_{2}, S_{3}$ and $S_{4}$

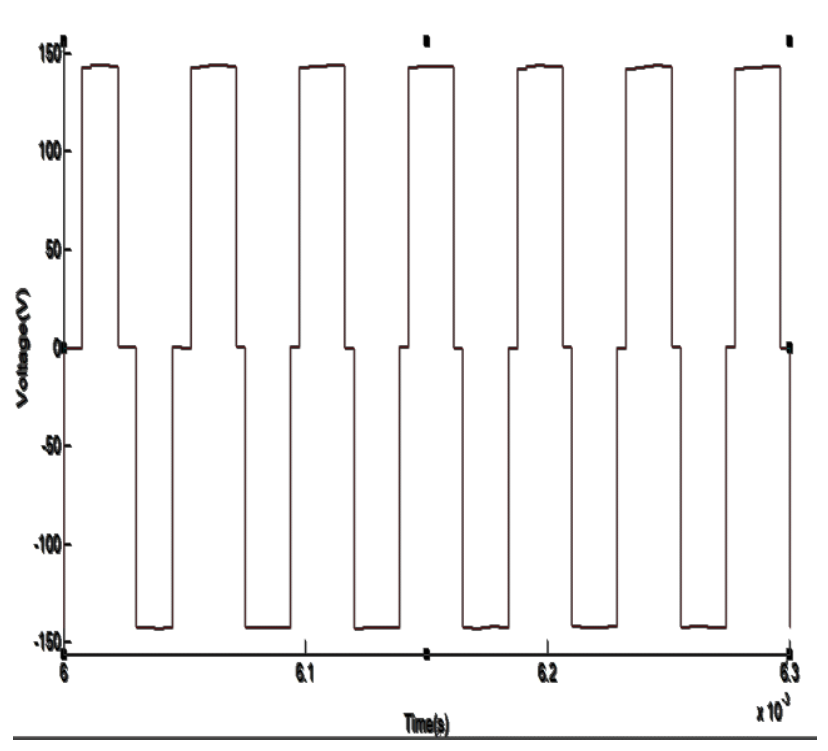

Fig. 9: Voltage across RL 


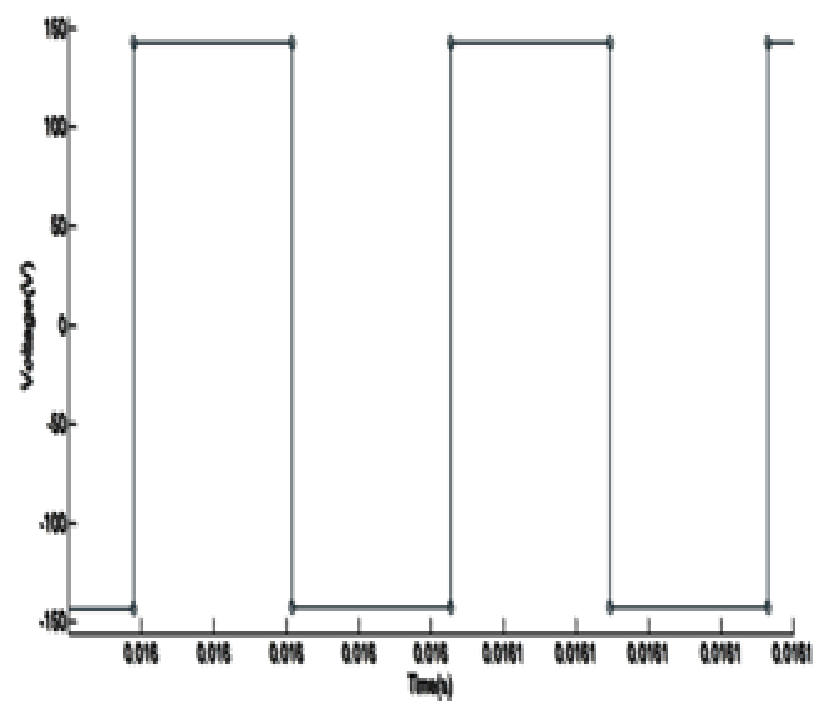

Fig. 10: Voltage across RLC

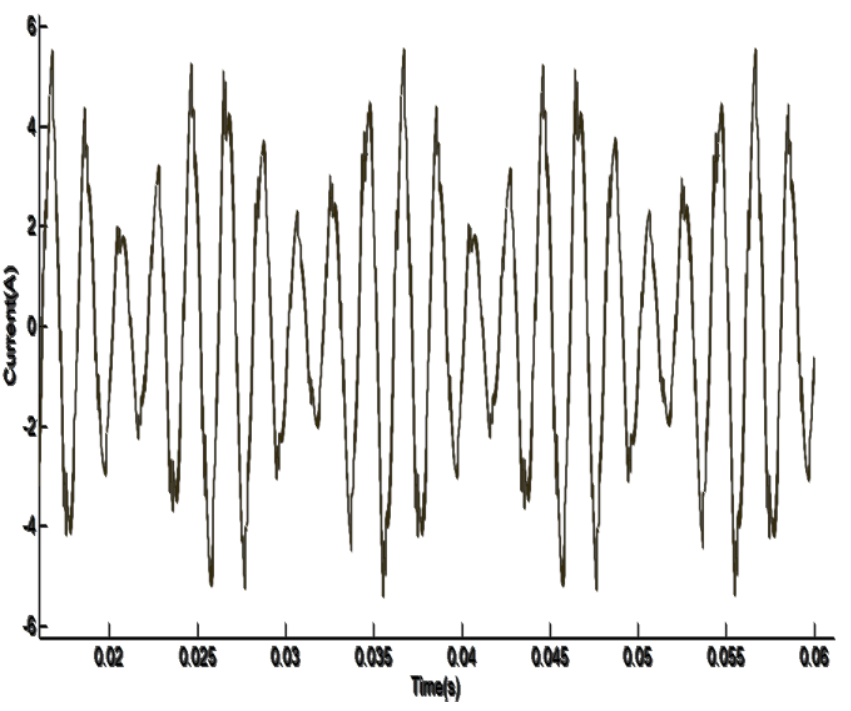

Fig. 11: Current through RL

It is noted that the phase-shift control technique is controls the power by varying the phase shift angle the output also varies such that when $\alpha$ increases continuously the load voltage as well the current decreases proportionately.

\section{Conclusion}

The Phase - Shift controlled SSB-Integrated inverter has been proposed for the IH applications and its feasibility of operation by control circuit is developed using the Simulink Matlab software and the simulated results has described and proven that by varying the phase shift angle the voltage across the load and current through the load varies proportionately.

\section{References}

[1] S. M. W. Ahmed, M. M. Eissa, M. Edress, and T. S.AbdelHameed, "Experimental investigation of full bridge series resonant inverters for induction-heating cooking appliances," 4th IEEE Conference on Industrial Electronics and Applications, ICIEA 2009, pp.3327-3332, 2009.

[2] M. Miyamae, T. Ito, K. Matsuse, and M. Tsukahara, "Performance of a high frequency quasi-resonant inverter with variable-frequency output for induction heating," IEEE 7th International Power Electronics and Motion Control Conference, 2012 .
[3] A. Fujita, H. Sadakata, I. Hirota, H. Omori, and M. Nakaoka, "Latest developments of high-frequency series load resonant inverter type built-in cooktops for induction heated all metallic appliances," IPEMC' 2009, pp. 2537-2544, 2009.

[4] N. A. Ahmed and M. Nakaoka, "Boost-half-bridge edge resonan soft switching PWM high-frequency inverter for consumer induction heating appliances," IEE Electric Power Applications, Vol. 153, No. 6, pp. 932-938, Nov. 2006.

[5] O. Jimenez, O. Lucia, I. Urriza, L. A. Barragan, and D Navarro, "Design and evaluation of a low-cost high-performance $\Sigma$ $-\triangle \mathrm{ADC}$ for embedded control systems in induction heating appliances," IEEE Trans. Ind. Electron. Vol. 61, No. 5, pp. 2601-2611, May 2014.

[6] H. Sarnago, O. Lucia, A. Mediano, and J. M. Burdio, "Direct AC-AC resonant boost converter for efficient domestic induction heating applications," IEEE Trans. Power Electron. Vol. 29, No. 3, pp. 1128-1139, Mar. 2014

[7] S.V. Manikanthan , T. Padmapriya "An enhanced distributed evolved node-b architecture in 5G tele-communications network" International Journal of Engineering \& Technology (UAE), Vol 7 Issues No (2.8) (2018) 248-254.March2018.

[8] S.V.Manikanthan and K.srividhya "An Android based secure access control using ARM and cloud computing", Published in Electronics and Communication Systems (ICECS), 2015 2nd International Conference on 26-27 Feb. 2015Publisher:IEEE,DOI: 10.1109/ECS.2015.7124833.

[9] T.Padmapriya and V.Saminadan, "Utility based Vertical Handoff Decision Model for LTE-A networks", International Journal of Computer Science and Information Security, ISSN 1947-5500, vol.14, no.11, November 2016 